\title{
LA HISTORIA EN EL TEATRO DE ERNESTO CABALLERO
}

\author{
THE HISTORY IN THE THEATRE OF ERNESTO CABALLERO
}

FERNANDO DOMÉNECH RICO

Real Escuela Superior de Arte Dramático / ITEM

\begin{abstract}
Resumen
Ernesto Caballero, uno de los dramaturgos más importantes de la generación del cambio de siglo, ha desarrollado a lo largo de su carrera un tipo de teatro histórico que se caracteriza por su variedad formal y por la coherencia de su visión de la Historia como un relato de los oprimidos y de los olvidados por el discurso del poder.

Palabras clave: Teatro histórico; Ernesto Caballero; teatro español contemporáneo.
\end{abstract}

\section{Abstract}

Ernesto Caballero, one of the most important playwrights of the generation of turn of the century, has developed throughout his career a type of historic theater that is characterized by its formal variety and consistency of his vision of history as a story of the oppressed and forgotten by the discourse of power. Key words: Historic Theatre; Ernesto Caballero; Contemporary spanish Theatre.

\section{INTRODUCCIÓN}

El reciente estreno de Reina Juana ha vuelto a traer a la luz una de las facetas fundamentales de la actividad teatral de Ernesto Caballero, faceta que había quedado oculta en los últimos años por su brillante labor como director de escena y como gestor cultural al frente del Centro Dramático Nacional. Ernesto Caballero es, efectivamente, un escritor, uno de los autores más importantes del teatro español en el cambio del siglo XX al siglo XXI. Si en los últimos años este aspecto destacaba menos era a raíz de una decisión del propio Ernesto Caballero para dedicarse con más intensidad a su puesto al frente del Teatro Nacional.

Desde su primer estreno, una versión pop de La vida es sueño, titulada Rosaura, el sueño es vida, mileidi, que subió a las tablas en 1983, Ernesto Caballero ha seguido con ejemplar constancia y en circunstancias diversas - a veces favorables, las más adversas escribiendo y estrenando las más de cincuenta obras que forman a día de hoy el corpus de su producción dramática. Menos que Lope de Vega, pero más que Shakespeare. Alguna de ellas ha supuesto un hito en el discurrir del teatro español de su momento ${ }^{1}$.

\footnotetext{
${ }^{1}$ Para una visión general de la carrera dramática de Ernesto Caballero se puede consultar mi Introducción a Auto. Sentido del deber. Naces consumes mueres (Doménech, 2014).
} 
En 1988 el reestreno de Squash en el Círculo de Bellas Artes de Madrid supuso su consagración gracias a la crítica que publicó Fernando Lázaro Carreter en Blanco y Negro (Lázaro, 1988), saludando a un nuevo escritor que para él representaba la auténtica alternativa a las dos formas teatrales existentes en el momento, la del teatro público y la del teatro comercial. Sería, con todo, el estreno de Auto en 1992 el que consagraría a Ernesto Caballero como uno de los dramaturgos fundamentales de su generación. En palabras de César Oliva:

\begin{abstract}
A Ernesto Caballero se le debe otro de los textos emblemáticos del momento, Auto (1992), excelente experiencia cargada de elementos alegóricos, aunque de sencilla expresión escénica. Cuatro personajes se presentan en una ambigua sala de espera, con la pretensión de justificar las causas del accidente que acaban de sufrir. Sin más elementos decorativos que un simple banco, los cuatro pasan de sentirse extrañados ante esa situación a acusarse mutuamente del origen del suceso. De medias palabras se pasa a una notable tensión, que termina por romperse al comprobar, ellos y el espectador a un tiempo, que el lugar de sus debates no es otro que la antesala del más allá, en donde pierde sentido todo cuanto antes sucedió. Esta inevitable referencia al mundo superrealista de Azorín es mérito añadido a la obra, que pasa por descubrir una nueva forma de plantear situaciones antes desarrolladas de manera más convencional (Oliva, 2004: 171).
\end{abstract}

Desde esas fechas, Ernesto Caballero no ha dejado de escribir, de estrenar y publicar decenas de obras dramáticas. Alguna de ellas ha tenido un notable éxito comercial, como Te quiero, muñeca. Otras, a pesar de su extraordinaria oportunidad, han pasado sin pena ni gloria por los escenarios, como es el caso de Tierra de por medio. Muchas de ellas han recibido el aplauso del público y han merecido la atención de los estudiosos. Existen ya tesis doctorales (López Martínez, 2014) y numerosos estudios académicos sobre el teatro de Ernesto Caballero (Pérez-Rasilla, 2003). Hay, no obstante, una serie de obras que han recibido poca atención de la crítica especializada, entre otras razones porque no han gozado tampoco de la atención de los productores teatrales ni de los editores. Algunas no se han estrenado nunca y no se pueden encontrar con facilidad; varias siguen inéditas.

Y entre ellas hay un grupo de piezas en que el autor mantiene una línea dramática que aparentemente se sale de los parámetros que en general sirven para definir su obra. Son las obras de tema histórico, de las que un buen ejemplo es precisamente su último estreno, Reina Juana.

\title{
2. TRES OBRAS EDITADAS.
}

\section{¡Santiago (de Cuba) y cierra España!}

En Santiago de Cuba se libraron dos de las batallas decisivas de la guerra hispano-norteamericana que acabó con la derrota española y la pérdida de los restos del imperio colonial en 1898. El día 1 de julio se libró en sus alrededores la batalla de la loma de San Juan, tomada por las tropas norteamericanas tras duros combates. Y el 3 de julio, a la salida de la bahía de Santiago, la flota del contraalmirante Cervera fue hundida por la del almirante Sampson, dejando a todo el ejército español a merced de 
las tropas estadounidenses. Tras la pérdida de la flota, Santiago de Cuba se rindió el 16 de julio. En diciembre España firmó con Estados Unidos el Tratado de París por el que cedió a la nueva potencia Cuba, Filipinas y Puerto Rico.

El "desastre del 98" supuso no solo una derrota en la guerra contra un país sin tradición militar al que no se consideraba capaz de derrotar al glorioso ejército español. Fue también el punto en que se manifestó una aguda crisis de conciencia que halló su mejor expresión en un brillante grupo de intelectuales a quienes Azorín bautizó como "Generación del 98".

En 1998, el año del primer centenario, Ernesto Caballero, entonces director asociado del Teatro de La Abadía, escribe y estrena en este espacio una amarga revisión de los sucesos del 98, que algún crítico con poco criterio consideró efecto de la "cultura de la subvención". Porque en la obra de Caballero no hay exaltación de valores patrios ni melancólica celebración de glorias literarias surgidas de la dolencia de España. ¡Santiago (de Cuba) y cierra España!, por el contrario, es una airada requisitoria contra una España dominada por una oligarquía que, si mantenía hacia el exterior una fachada de dignidad patriótica, en realidad lo que defendía en las guerras coloniales eran sus pingües negocios. El protagonista, por ello, es el pueblo. Con una mirada furiosa, Ernesto Caballero recupera para el público de 1998 el desastre que supuso aquella guerra para el pueblo español y el cubano. La eterna carne de cañón que lo mismo servía para morir en la manigua que para trabajar las tierras del señor o, convertidas las madres campesinas en amas de cría, amamantar a los cachorros de los grandes propietarios (Doménech, 1999).

"Linterna mágico-satírica” es el subtítulo que Ernesto Caballero dio a su obra. Con él ofrece una clave acerca del género que le sirvió como modelo para recrear ese mundo del 98. La "linterna mágica" era un artefacto óptico propio de las ferias y verbenas populares en que el público podía ver a través de un visor diversas escenas que recreaban el París de la Tour Eiffel, el Palazzo Ducale de Venezia rodeado de góndolas, el desierto del Sahara con una caravana atravesándolo... Esta fórmula, junto con la tradición de la revista política de la época de la Restauración, le sirve a Ernesto Caballero para crear una estructura de cuadros en donde se unen los cantables (algunos tan ingeniosos como el Tango del cangrejo, tomado del sainete lírico El mozo crúo) con documentos reales y las ficciones más extravagantes. El resultado es uno de los textos que más se acercan al cabaret berlinés de entreguerras y revela una fuerte influencia de Bertolt Brecht, autor del que Ernesto Caballero acababa de estrenar una obra miscelánea en el Teatro de La Abadía, Brecht cumple cien años.

Esta misma estructura de linterna mágico-satírica la aplicó Ernesto Caballero a dos obras posteriores, El descenso de Lenin y El sastre del rey. Sin embargo, la profusión de elementos fantásticos los alejan del equilibrio entre lo histórico y lo imaginario que se puede encontrar en ¡Santiago (de Cuba) y cierra España!.

Esta es una de las obras de Ernesto Caballero que ha tenido una discreta fortuna editorial. Después de su estreno en el Teatro de la Abadía el texto se publicó en 1999 en la revista Acotaciones. En 2002 la publicó la SGAE dentro de su colección “teatroautor". 


\section{En La Roca}

En febrero de 1937 la policía de Franco detuvo en Córdoba, mientras asistía a una corrida de toros, a un periodista inglés. Era Harold Adrian Russell Philby, más conocido como Kim Philby. Lo soltaron en seguida al comprobar que era un simpatizante de la causa fascista, miembro de la Liga de Amistad Anglo-Alemana y redactor de una revista filonazi. Con tales credenciales Philby siguió toda la Guerra Civil como corresponsal del diario conservador The Times y llegó a ser condecorado por Franco con la Cruz Roja al Mérito Militar.

Lo que no sabían ni Franco ni su policía, como no lo supieron durante décadas los servicios secretos ingleses y americanos es que Kim Philby, el mejor espía del siglo $\mathrm{XX}$, era un agente soviético, marxista convencido, que había abrazado la causa comunista mientras estudiaba en Cambridge, y que había sido destinado a España por el NKVD para asesinar a Franco. Philby, al ser detenido, se deshizo de su libreta de claves. Para poder seguir con su misión en España necesitaba una nueva, que le fue entregada por su amigo y compañero Guy Burgess en el hotel The Rock, de Gibraltar, en marzo de 1937. Eran los años en que se estaban produciendo las grandes purgas de la vieja guardia revolucionaria conocidas como "Procesos de Moscú".

En La Roca recrea esta entrevista entre los dos viejos amigos de Cambridge, ambos miembros de la clase alta británica y espías al servicio de Stalin. Mientras beben incansables un whisky tras otro, los dos amigos se observan, tratan de averiguar las intenciones del otro y-más importante aún- las intenciones del NKVD. ¿Por qué quieren los jefes de Moscú que Philby mate a Franco, sabiendo que es un intelectual sin ninguna experiencia en este tipo de acciones? ¿Es una prueba? ¿Es una trampa?. No hay respuestas en esa noche en que los dos amigos plantean ante el espectador las preguntas básicas de la acción revolucionaria, como en un impensado homenaje a Lenin: ¿Qué hacer? (Doménech, 2010).

Al contrario que otras obras históricas del autor, En La Roca tiene el aspecto de un drama tradicional, entre Chéjov e Ibsen: dos personajes que hablan y hablan sin tomar una decisión, sin que sea evidente el discurrir de la acción dramática. Pero Ernesto Caballero cierra su obra con un giro espectacular que da un nuevo sentido a este diálogo de caballeros. De pronto, la noche de 1937 se amplía hasta convertir las pocas horas de entrevista de los dos aprendices de espías para englobar todo el tiempo de sus vidas, de modo que ellos mismos puedan conocer el curso de la Historia y el discurrir de sus propias historias, con todos sus errores y todos sus fracasos:

Vive tu vida y deja que los españoles, como ellos mismos dicen, soporten su cruz... Créeme, de nada serviría tu heroico gesto. La suerte de Europa ya estaba echada. Los italianos acabaron con Mussolini. Hitler no tuvo más remedio que pegarse un tiro. ¿Qué importa si Franco murió en la cama décadas más tarde? La Historia es la que es. (Caballero, 2010: 169-170).

¿Es la cínica conclusión de un espía borracho después de una noche de confesiones? ¿O es la pétrea afirmación de un marxista convencido que rechaza la acción individual y confía en la inexorable marcha de la Historia que preconizaba Karl Marx? Ernesto Caballero no lo aclara. Quizás sea ambas cosas a la vez. 
En La Roca fue estrenada por Ignacio García en el Teatro Español en 2010. El texto, con abundancia de información sobre la puesta en escena, fue publicado por el mismo Teatro Español en ese mismo año.

\section{Aliento azul}

En 1914 el estudiante de Filosofía Ludwig Wittgenstein, hijo de un industrial austriaco dueño de una gran fortuna, se alista como voluntario en el ejército austrohúngaro al declararse la I Guerra Mundial. Destinado al frente ruso, participa en la ofensiva sobre Galitzia, que acabó en una terrible derrota para los austro-húngaros. En ese mismo frente se encuentra como médico militar Georg Trakl, a quien el joven Ludwig había conocido en Viena. Trakl, farmacéutico y poeta, el más importante del movimiento expresionista, se suicida en Cracovia el 3 de noviembre de 1914 con una sobredosis de cocaína.

Wittgenstein participa como soldado y posteriormente como oficial en distintos frentes de guerra hasta que es capturado por los italianos en 1917 y pasa dos años en un campo de prisioneros. En los años de la guerra escribe sobre matemáticas y lógica siguiendo las directrices aprendidas en Cambridge en los años 1912-1913 al lado de su maestro Bertrand Russell. A su vuelta a Inglaterra, presenta estos apuntes como tesis doctoral con el nombre de Tractatus Logico-Philosophicus, una de las obras fundamentales de la filosofía del siglo XX.

La obra de Ernesto Caballero nos presenta al soldado raso Ludwig Wittgenstein en la cubierta de una barcaza, el Goplana, que el ejército austro-húngaro utiliza para cruzar el Vístula bajo el fuego de la artillería rusa en la huida de Cracovia tras la derrota en noviembre de 1914. Solo, aislado del resto de sus compañeros, seres embrutecidos (muy en la línea del bravo soldado Schweik) que lo ven como un hombre huraño y un poco alucinado, su único acompañante es un libro, el Evangelio, de León Tolstoi, que encontró entre unas ruinas. El texto es un desesperado monólogo de Wittgenstein, que trata de hablar con un dios lejano y siente la tentación de imitar a su amigo Trakl y acabar con su vida. Los versos de "Para el joven Elis", de Trakl, se enredan con sus propias palabras:

Tu cuerpo es un jacinto

en el que hunde un monje los dedos de cera

una negra gruta es nuestro silencio

de ella sale un dulce animal a veces

y baja lentamente los párpados pesados

Sobre tus sienes gotea negro rocío

el oro último de caducas estrellas (Caballero, 2004: 41).

Sin embargo, la desesperanza se va convirtiendo en una extraña lucidez que le permite desdeñar todo lo que la Filosofía ha sido hasta entonces y descubrir las secretas relaciones entre las palabras y las cosas. Este momento de lucidez es el "aliento azul" de dios, que la permite entender que él mismo es un actor que trata de representar a 
Ludwig Wittgenstein en su huida de Cracovia en noviembre de 1914. Porque, como expresó Calderón, el mundo es un teatro y todos somos actores de nuestra propia vida: el teatro después de todo es

un modelo a escala reducida

de una determinada realidad

como esas maquetas

que en los juicios se disponen

para dilucidar los accidentes de tráfico

eso es

debe existir una relación lógica

entre las palabras

y los objetos que nombran

la misma relación entre las cosas reales

y su representación

en una maqueta o en un teatro (Caballero, 2004: 45).

Y así, ese actor es un Wittgenstein espurio descubre su proposición fundamental: pero este es un Wit espurio un Wit falso

el verdadero Wit que viajó en el Goplana

está reflejado en los diarios secretos

nada de lo que estoy diciendo lo dije

y sin embargo

ahora soy el único Wit real

inspirado por el recuerdo de aquel otro Wit

estas fisuras las provoca la palabra

porque es ella finalmente lo único real lo único

que construye lo real

así por ejemplo ahora podría expresar

la siguiente proposición

impacto de un obús en el casco del Goplana

el agua entra a raudales vamos a naufragar

alerta suenan las alarmas (Caballero, 2004: 46-47).

Aliento azul es, pues, una obra de gran densidad que se adentra en los meandros del pensamiento de uno de los filósofos que más ha influido en el pensamiento moderno. En ella Ernesto Caballero vuelve a temas que le han preocupado en toda su obra, como es la relación entre el teatro y la vida, entre el personaje y el actor. Y lo hace con una obra sin concesiones escrita en verso libre, una de las fórmulas preferidas por su autor desde Auto.

Se publicó en el año 2004 en un dossier dedicado a "El esperpento de la guerra" de la revista Primer Acto, en donde se unían el análisis del esperpento valleinclaniano con una serie de obras contemporáneas dedicadas a mostrar el despropósito de la guerra. La obra de Ernesto Caballero estaba acompañada de la dramaturgia realizada por el 
mismo Caballero sobre la película En tierra de nadie, del cineasta bosnio Danis Tanovic, y de la obra El muro, de José Monleón. Las obras no se acompañaban de ningún estudio preliminar. Daniel Moreno realizaba una entrevista a Ernesto Caballero en donde no se hacía mención de Aliento azul. Nunca se ha estrenado.

\section{CUATRO OBRAS INÉDITAS}

\section{Leandro, o La búsqueda del equilibrio}

El 24 de enero de 1806 Leandro Fernández de Moratín estrenaba en el Coliseo de la Cruz de Madrid la comedia El sí de las niñas. El éxito fue clamoroso: la comedia se mantuvo con llenos casi totales durante veintiséis días, y solo la retiró de las tablas el final de la temporada y el cierre de los teatros. Atrás quedaban para Moratín los tiempos de pobreza, de lucha por conseguir una reforma teatral tantas veces iniciada y nunca conseguida, los años de peregrinaje y dulces amoríos. Con el triunfo de $E l$ sí de las niñas se abría un nuevo camino al teatro español y se daba pie a la esperanza de una España nueva, más culta, más abierta y más tolerante, la España ilustrada que no había cuajado todavía después de todos los esfuerzos del siglo de las Luces.

Dos años después, todas aquellas esperanzas quedaron destruidas por la invasión napoleónica y la guerra que tuvo mucho de contienda civil, preludio de las que asolarían el país durante el siglo XIX. Los intelectuales españoles se vieron enfrentados a un dilema desgarrador: divididos entre la confianza en la razón, en los valores de la Revolución Francesa que tímidamente apuntaban en la corte del rey José I, y la defensa de la nación que suponía aceptar como rey a Fernando VII, unos y otros tomaron caminos equivocados. Los que se pusieron del lado del Deseado, acabaron en el cadalso o el exilio. Quienes, como Moratín, aceptaron la monarquía bonapartista, pagaron con humillaciones su "afrancesamiento" para acabar también en un destierro del que no volverían.

La vida de Leandro Fernández de Moratín supone una peripecia vital singular que es a la vez símbolo y emblema de toda una época preñada de posibilidades que acabarían diluyéndose en la nada. En él reconocemos, por su empeño en alcanzar un equilibrio imposible entre la razón y la pasión, entre la modernidad y la tradición, la tragedia de la España ilustrada.

En 2006, coincidiendo con el segundo centenario del estreno de El sí de las niñas, efemérides que pasó sin pena ni gloria por los escenarios españoles, Ernesto Caballero escribe Leandro o la búsqueda del equilibrio, donde trata de recoger toda la peripecia de un autor en el contexto de una época fundamental para la cultura española. Ese mismo año dirige para la Compañía Nacional de Teatro Clásico un montaje de distintos sainetes de Ramón de la Cruz que tuvo un éxito extraordinario tanto de público como de crítica. En consecuencia, en 2008 la CNTC le encarga la puesta en escena de una de las obras más conocidas de Moratín, La comedia nueva. En la presentación que escribió 
Caballero para el programa mostraba su postura ante la comedia y ante todo lo que significó Moratín en su momento:

En definitiva, hemos llevado a cabo una crítica radical de una obra emblemática de nuestra literatura dramática desde un lugar privilegiado: la práctica artística. Y así, este diálogo escénico con el pasado nos ha llevado inevitablemente a interrogarnos sobre distintos aspectos del ideario ilustrado, movimiento que preconizaba la emancipación social desde unos postulados de progreso que la burguesía emergente demandaba y que, en el caso español, se vieron frustrados irremisiblemente con las tristes e imperecederas consecuencias de todos conocidas. Una exigencia reformista fundamentada en el estudio, la ciencia y la fuerza de la razón que cristalizó en una concepción de práctica política bautizada posteriormente como despotismo ilustrado, y donde se concitaron las luces de un proyecto de progreso con las sombras de la exclusión de las clases populares de toda actividad política, social y cultural, o el confinamiento de la mujer al ámbito de lo doméstico.

¿Adónde han conducido finalmente todos estos sueños de la Razón? Monstruos terriblemente familiares y reconocibles que acaso asomen de vez en cuando en esa pequeña caja escénica que preside las salas de estar de nuestros entrañables hogares posmodernos (Caballero, 2008: 12-13).

Como expresión de esta doble mirada sobre la Ilustración, Caballero escribe un retrato de Moratín que no deja al margen ninguna de las complejidades de un carácter ambiguo, de gran luminosidad y con muchas zonas oscuras. Pero a la vez es una obra de amplitud tolstoiana: ante el espectador, como en un gran fresco histórico, desfilan momentos históricos, personajes que acompañaron la vida de Leandro o se cruzaron en ella. Pero son sobre todo las preocupaciones y los anhelos de una época lo que se va desgranando en estas escenas menos episódicas de lo que parece en una primera visión: las discusiones sobre el teatro, sobre el arte y la política, son solo capítulos de una intensa reflexión acerca de la España que le tocó vivir a Moratín y quizás también a nosotros.

$Y$ en medio de este panorama de una época, se destaca el retrato de un personaje complejo, enfrentado a sus realidades y a sus fantasmas, un hombre perpetuamente oscilante entre su acercamiento al poder y su desprecio por él, entre su ansia de amores y su prevención ante el amor, entre su afán combativo y su tendencia al retiro. Vemos así al Moratín indeciso de sus primeros años, al asiduo frecuentador de prostíbulos, al reformador del teatro, al enamorado sin saberlo, al revolucionario desorientado por los horrores de Francia, al admirador de Shakespeare, al melancólico exiliado que sólo espera la muerte...

La obra de Ernesto Caballero se mueve con fluidez entre la acción y la reflexión, va de lo personal a lo colectivo, para ofrecernos, en un cuadro de grandes dimensiones, la pintura que bien se podría titular Figura en un paisaje. Una obra que busca entender a Leandro Fernández de Moratín y entender lo que configura todavía el ser de los españoles.

Leandro, o la búsqueda del equilibrio no se ha representado nunca. Sigue inédita.

\section{Josu y los tiburones}

El 12 de marzo de 1956 el jurista y profesor Jesús Galíndez, representante del PNV en el Gobierno Vasco del exilio, fue secuestrado frente a su domicilio, en la 
Quinta Avenida de Nueva York, por orden del dictador Rafael Leónidas Trujillo. En el secuestro participaron los servicios secretos norteamericanos, para los cuales había trabajado Galíndez.

Nunca se ha encontrado el cadáver de Galíndez. Se sabe, no obstante, que fue trasladado a Santo Domíngo, donde fue torturado y asesinado. Poco antes de su secuestro había presentado en la Universidad de Columbia su tesis doctoral La era de Trujillo: un estudio casuístico de dictadura hispanoamericana. Los encargados de su secuestro desaparecieron también.

En 2005 Ernesto Caballero escribe Josu y los tiburones. La obra está encabezada por una cita de Bertolt Brecht: "Si los tiburones fueran hombres..." De estas palabras y de la casi completa seguridad de que el cadáver de Galíndez fue arrojado al mar desde un avión para que lo devoraran los tiburones parte Josu y los tiburones. Los escualos que rodean a Galíndez en el fondo del Caribe forman un grotesco tribunal que va recordando toda la peripecia del profesor vasco hasta su muerte. Entre el recuerdo y la alucinación Josu va exponiendo sus años en España, la guerra, el exilio, su estancia en la República Dominicana, sus estudios en Nueva York. Los tiburones, que oscilan entre la crueldad primaria y el descarado sarcasmo, se transforman en todas las personas que han acompañado a Galíndez en su vida, pero sobre todo en el grupo de torturadores al servicio de Trujillo que lo asesinan.

Se trata de una de las obras más estremecedoras de Ernesto Caballero. Más que la de Bertolt Brecht, se siente en sus páginas la herencia de Franz Kafka. Y sin embargo, el autor no renuncia a darle un halo poético, no solamente por su habitual escritura en verso libre, sino por la misma estructura de la obra, en forma de oratorio, que el autor repetirá en otras ocasiones. Claro que se trata de una poesía feroz, llena de una brutal ironía (esta sí, muy brechtiana), como el momento en que los tiburones miman los versos de Galíndez:

Uno de los tiburones recita unos versos de JG en tanto los demás llevan a cabo una ingenua pantomima.

TIB.- "Cuando muera conducidme

A aquel monte de mi pueblo,

Bajo un roble solitario

Entre nubes y recuerdos.

Llevadme a dormir a Amurrio

Que estoy cansado, y no puedo

Detenerme en el camino;

Caeré al azar, viajero.

Llevadme, llevadme allí

Si caminando aún muero

A la colina empinada

Bajo el roble de mis sueños." 
JG.- ¿Por qué os burláis?

TIB.- Porque no sabemos hacer otra cosa.

El mundo nos ha hecho así,

Sanguinarios y crueles.

Nosotros no tenemos la culpa:

Somos víctimas, victimas del Reino animal,

Lo mismo que el pueblo tuyo lo es de la Historia.

Pobres de nosotros las víctimas. Ñam. Ñam (Caballero, 2005).

Quizás por esta extraña mezcla de poesía y fiereza la obra no se ha estrenado nunca. Tampoco ha sido publicada.

\section{Oratorio para Edith Stein}

En agosto de 1942 la deportada 44075 fue gaseada en una de las cámaras del campo de Auschwitz-Birkenau. Sus restos fueron calcinados en uno de los hornos crematorios y sus cenizas se esparcieron, con las de otros miles, en los campos adyacentes.

La deportada 44075 era una monja católica, Sor Teresa Benedicta de la Cruz, que había nacido en Breslau en 1891 como Edith Stein. Pertenecía a una acaudalada familia judía. Estudiante de Filosofía de gran brillantez, fue una de las mejores discípulas de Edmund Husserl. A raíz de la lectura de Santa Teresa se convirtió al catolicismo y se hizo monja carmelita. Ni esto ni el traslado a un monasterio holandés impidió que los nazis la detuvieran y la internaran en distintos campos hasta llevarla a Auswichtz, donde fue asesinada. En 1998 fue canonizada por el Papa Juan Pablo II.

En 2011 se estrena en el Teatro Español de Madrid un espectáculo titulado Santo, formado por tres obras de Ernesto Caballero, Ignacio García May e Ignacio del Moral, todas ellas dirigidas por Ernesto Caballero y protagonizadas por Aitana Sánchez Gijón. El propósito de los tres autores era reflexionar sobre el bien en un mundo en donde el mal siempre ha tenido mejor prensa. La obra de Ernesto Caballero se llamaba Oratorio para Edith Stein. El autor explicaba el carácter de este Oratorio en una nota situada al final del mismo:

Este Oratorio es un trabajo dramatúrgico que contiene algunas citas literales de diversa procedencia: desde Teresa de Ávila hasta el propio testimonio de Edith Stein. Las escenas que dan cuenta de su peripecia vital se han elaborado con las referencias que ella misma o personas cercanas a la santa nos aportan. El interrogatorio del oficial alemán es completamente ficticio (Caballero, 2011).

La forma de oratorio ha sido una de las preferidas por Ernesto Caballero a la hora de abordar la temática histórica. No es difícil explicar por qué. La forma libre, no determinada por la necesidad de someterse a la acción dramática, con sus puntos de inflexión, su nudo y su desenlace, así como la posibilidad de hacer intervenir a distintos personajes en cualquier momento de la función, ofrece grandes posibilidades para recrear momentos históricos en donde no importa tanto la peripecia como el mundo reflejado. No podemos dejar de lado la tradición musical del oratorio, que se ajustaría además a la historia de una santa católica como Santa Teresa Benedicta de la 
Cruz. Pero me parece mucho más importante otra tradición laica, la que viene de la obra fundamental sobre el Holocausto, La indagación, de Peter Weiss, que se subtitula precisamente "Oratorio" y que ofrece numerosos puntos de contacto con la obra dedicada por Ernesto Caballero a una de las víctimas de la Shoah.

De alguna manera, el Oratorio para Edith Stein tiene una cierta deuda con el teatro-documento. Como aclara el propio Caballero, una parte importante de texto está tomado directamente de escritos de la autora, de los personajes que la rodearon y de Santa Teresa. Sin embargo, para el autor es mucho más importante la parte imaginada, la recreación del improbable interrogatorio a que es sometida Edith en el campo de exterminio. La obra no recrea una vida, sino un momento climático: aquel en que la monja se enfrenta a la verdad del sufrimiento y la muerte, el momento que da sentido a toda su vida.

Escrita para ser representada como parte de un espectáculo, la obra de Ernesto Caballero es de una gran concisión, seguramente la más breve de las que hemos examinado. Por su forma de oratorio, por la escritura en verso libre, incluso por su enfoque de un personaje enfrentado a la trascendencia, se relaciona sobre todo con Aliento azul. A pesar del estreno, sigue inédita.

\section{Reina Juana}

El 12 de abril de 1555 moría en su palacio-cárcel de Tordesillas la reina Juana I de Castilla. Había vivido encerrada desde 1509, primero por orden de su padre, el rey Fernando el Católico, y más tarde por su hijo, Carlos I, el Emperador. En los últimos tiempos se había encargado de confortar a la reina y de hacerla volver al redil de la Iglesia Católica (Juana se negaba a recibir los sacramentos) el jesuita Francisco de Borja, que después sería elevado a los altares, y que había sido anteriormente un activo consejero político y cortesano del Emperador como Duque de Gandía.

Reina Juana, dirigida por Gerardo Vera e interpretada por Concha Velasco, es por ahora la última obra de Ernesto Caballero que ha llegado a las tablas. Toda la crítica ha señalado la importancia de la actriz en este éxito. Marcos Ordóñez, en su crítica de El País. Babelia, escribe:

Concha Velasco tiene la edad y la fuerza del personaje. La palabra "entrega" es la primera que viene a la cabeza y es cierta, pero hay que señalar que se trata de una entrega tan rotunda como radiante. La Velasco no te hace ver el esfuerzo, cosa siempre muy de agradecer. Exhala la felicidad de estar haciendo teatro con un texto a la medida, un personaje espléndido, y en un espacio ideal, a pocos metros del público. Se muestra, como siempre, comunicativa, llena de humanidad, con una dicción clara y vigorosa. Transmite una emoción viva y sincera, y esa simpatía arrasadora que es su marca de fábrica: hasta interpretando a una asesina serial caería simpática. Son también sus bazas una gran claridad expositiva y su capacidad de encantar, como quien cuenta un cuento (Ordóñez, 2016)

Pero estos elogios a la interpretación de Concha Velasco dejan entrever - a veces de forma expresa - que el texto de Ernesto Caballero tiene también su parte en el éxito del montaje. El personaje de Juana ha atraído a numerosos dramaturgos españoles 
desde que Tamayo y Baus estrenara Locura de amor en 1855. Sin embargo, han sido el cine y la televisión quienes más han contribuido a popularizar esta figura histórica. Juan de Orduña, con su película Locura de amor, de 1948 interpretada por Aurora Bautista, consiguió una de las cimas del cine histórico neo-imperial del primer franquismo. Más cercana fue la versión de Vicente Aranda, de 2001, reescritura de la obra de Tamayo y de la película de Orduña. El personaje de la reina estuvo interpretado con notable acierto y fuerza por Pilar López de Ayala. Sin embargo, han sido las series de Televisión Española Isabel y Carlos, Rey Emperador y su secuela cinematográfica, La corona partida, en donde Juana estaba interpretada por Irene Escolar, las que más han traído a la memoria de los españoles actuales los avatares de la desdichada reina de Castilla.

Ernesto Caballero, por tanto, asumía al escribir el texto un reto importante: por un lado se beneficiaba de la popularidad del personaje histórico; por otro, podía fracasar por la saturación del público de obras recientes o recordadas sobre Juana la Loca. Caballero sale airoso al centrarse en un solo momento, el de la última noche de la reina, en Tordesillas, con un solo interlocutor que no habla y solamente sirve para recibir la heterodoxa confesión de Juana: el aspirante a santo Francisco de Borja. La tormentosa juventud de Juana, sus problemas con su hermoso e infiel esposo Felipe, las terribles relaciones con su padre y con su hijo, el episodio de los Comuneros, todo ello son solo recuerdos que se entrecruzan en la mente de la lúcida reina loca. Ya Benito Pérez Galdós había abordado esta misma situación en una de sus últimas obras, Santa Juana de Castilla, estrenada en 1918 por Margarita Xirgu, en que retrata a la reina en sus últimos momentos. Pero Galdós, siguiendo el esquema propio del teatro de su tiempo, crea un drama lleno de personajes, de acciones secundarias, de estructura clásica, mientras que Ernesto Caballero ha dejado la historia en el hueso, en la mínima expresión que representa el monólogo.

Quizás por ello la escritura de Reina Juana es de extraordinaria riqueza. Se acerca a las obras en forma de oratorio que hemos analizado páginas arriba: Aliento azul y Oratorio para Edith Stein. Sin embargo, se trata de un monólogo más tradicional que estas otras obras. El personaje rememora toda una época y a una gran cantidad de personajes a través de su palabra. Por ello el tono varía a lo largo del monólogo: a veces narrativo, otras profundamente dramático (la figura del santo antagonista es crucial en estos momentos), casi siempre lírica. En apariencia ese lirismo está más soterrado, ya que Caballero renuncia a escribir en verso, al contrario de lo que hace en otras obras. Pero en ocasiones escribe en una prosa tan rítmica que - quizás sin sentirlo - se le va al verso:

Por fin canta un gallo, se oyen las campanas...

me yergo del lecho y vuelvo a caer...

La luz no ha traído tregua que apacigüe

mi desasosiego... y ahora me siento

como un álamo débil en que se han incrustado

láminas de hielo por todo resquicio

de su esqueleto...

y el hielo es un vidrio que parte las ramas, 
el tronco y la sangre del mísero árbol

que aguanta inclemencias perdido en el monte... (Caballero, 2016)

Esta auténtica estancia, oculta tras la apariencia de la prosa, está escrita mayoritariamente en versos dodecasílabos con cesura tras la sexta. Es una métrica desusada pero no desconocida en la tradición poética hispánica. Rubén Darío y ValleInclán la utilizaron en distintas ocasiones, y el propio Ernesto Caballero escribió muchas de las acotaciones de Sentido del deber en dodecasílabos.

Reina Juana se estrenó en el Teatro Lope de Vega el 7 de abril de 2016 y supuso para autor, director y, sobre todo, para Concha Velasco un éxito apoteósico que se ha venido repitiendo en todos los lugares en donde se ha presentado. En el Teatro de la Abadía, de Madrid, donde se ha representado del 28 de abril al 12 de junio de 2016, se ha puesto en numerosas ocasiones el cartel de "No hay localidades".

\section{SENTIDO DE LA HISTORIA Y SENTIDO DE LAS HISTORIAS}

El repaso a todas estas obras muestra la variedad de enfoques, de estructuras dramáticas y hasta de intención en cada una de las obras históricas de Ernesto Caballero. Las hay que pretenden recoger todo el latido de una época; otras, por el contrario, se centran en un personaje y un momento concretos. Algunas se acercan al teatro-documento, otras son puro vuelo de la fantasía. Todas tienen un cierto sentido poético, pero en algunas de ellas lo lírico prepondera sobre lo dramático. Pero por encima de las diferencias, hay algo que las une: la constante preocupación de Ernesto Caballero por entender el ser y el discurrir de los seres humanos, y muy especialmente de esos extremados seres humanos llamados españoles.

La Historia, para Ernesto Caballero, no es un mero pretexto argumental. Al final de ¡Santiago (de Cuba) y cierra España, la alegórica Blanca Figura expone todo un programa ideológico y dramático en los versos que cierran la obra:

España tal vez solo ha sido

hombres y mujeres que

han tratado con esfuerzo

vivir la vida y no ser

solamente una bandera

o el relato que el poder

se inventa y que llama Historia.

La Historia está por hacer (Caballero, 2002: 117).

"El relato que el poder se inventa y que llama Historia". En esta frase con reminiscencias de Foucault parece estar la clave de muchas de las obras analizadas. Gran parte del drama histórico, desde el siglo XVIII, ha estado al servicio de un relato del poder. Se ha intentado crear una mitología patria, un discurso al servicio de las élites que justificara la situación del presente a través de una recreación heroica del pasado. Así se puede entender un filme histórico como Locura de amor, en donde se ensalza un pasado imperial y se defiende la españolidad de la reina loca frente a la 
conspiración internacional franco-borgoñona que vendría a ser como la conspiración judeo-masónica de la oratoria franquista.

Nada de eso interesa a Ernesto Caballero. Su visión de la Historia estaría entre Bertolt Brecht y Walter Benjamin, y muy especialmente en la visión que da este último en ensayos como Sobre el concepto de Historia. Conceptos como: "No hay nunca un documento de la cultura que no sea, a la vez, uno de la barbarie" (Benjamin, 2009: 144) no están lejos de la concepción de la Historia que muestra Caballero en sus obras. Pero si hay una propuesta de Benjamin que podría definir con precisión su teatro histórico, sería esta:

Articular históricamente lo pasado no significa conocerlo "tal como realmente ocurrió". Significa apoderarse de un recuerdo tal como fulgura en el instante de un peligro. [...] El peligro amenaza tanto al acervo de la tradición como a sus receptores. Para ambos, el peligro es uno y el mismo: convertirse en instrumento de la clase dominante (Benjamin, 2009: 142).

Uno de los grandes difusores de la filosofía de Benjamin en España ha sido Juan Mayorga, autor muy cercano a Ernesto Caballero, que estrenó La tortuga de Darwin en 2008. Mayorga, tanto en su obra dramática como en sus ensayos, ha defendido no ya la necesidad del teatro histórico, sino su inevitabilidad. En El dramaturgo como historiador afirma taxativamente: "El teatro fue probablemente el primer modo de hacer historia" (Mayorga, 2016: 154). Así, partiendo de la filosofía benjaminiana, Mayorga ha desarrollado un pensamiento sobre el carácter del teatro histórico desde una perspectiva renovada que se aleja tanto de la exaltación patriótica del pasado como de la visión historicista propia del marxismo tradicional:

Todos los hombres somos contemporáneos. Más allá de la condición histórica, hay la condición humana, la Humanidad. El teatro histórico -incluso el de vocación historicista- es una victoria sobre la visión historicista del ser humano según la cual este se halla clausurado en su momento histórico, del que es producto. Porque la condición de posibilidad del teatro histórico no es aquello que diferencia unos tiempos de otros, sino aquello que atraviesa los tiempos y que permite sentir como coetáneo al hombre de otro tiempo (Mayorga, 2016: 154).

Una convicción semejante late en las obras de Ernesto Caballero. La anulación del tiempo histórico que se da en muchas de sus obras de tema histórico tiene la función de romper la confianza del espectador en que está viendo "cosas del pasado". La Historia, como afirma la Blanca Figura, está por hacer. Y es el espectador, el que al revivir la peripecia de unos personajes que figuran hombres y mujeres de otro tiempo, el que construye, con ayuda del dramaturgo, las historias que forman la Historia.

\section{BIBLIOGRAFÍA}

\section{OBRAS CITADAS}

Caballero, Ernesto (1999): ¡Santiago (de Cuba) y cierra España!, en Acotaciones, 2 (enerojunio).

Caballero, Ernesto (2002): ¡Santiago (de Cuba) y cierra España!. (Linterna mágico-satírica). Prólogo de Fernando Doménech, Madrid, SGAE. 
Caballero, Ernesto (2004): Aliento azul. En Primer Acto, 304.

Caballero, Ernesto [2005]: Josu y los tiburones. [Inédita. Manuscrito del autor].

Caballero, Ernesto [2006]: Leandro, o la búsqueda del equilibrio. [Inédita. Manuscrito del autor].

Caballero, Ernesto (2010): En La Roca. Dirección Ignacio García. Madrid, Teatro Español.

Caballero, Ernesto [2011]: Oratorio para Edith Stein. [Ínédita. Manuscrito del autor].

Caballero, Ernesto [2016]: Reina Juana, [Inédita. Manuscrito del autor].

\section{ESTUDIOS}

Benjamin, Walter (2009): Estética y política. Traductores Tomás Joaquín Bartoletti y Julián Fava. Prefacio Ralph Buchenhorst, Buenos Aires, Las Cuarenta.

Caballero, Ernesto (2008): “Diálogo con la Ilustración”, en Leandro Fernández de Moratín: La comedia nueva, o el Café. Versión y dirección Ernesto Caballero. Edición Mar Zubieta, Madrid, CNTC, pp. 11-13.

Doménech Rico, Fernando (1999): “Ernesto Caballero cierra contra el 98", Acotaciones, 2, pp. 81-84.

Doménech Rico, Fernando (2010): “Poética de lo real (Seis calas en la obra teatral de Ernesto Caballero)", en Ernesto Caballero, En La Roca. Dirección Ignacio García. Madrid, Teatro Español, pp. 13-47.

Doménech Rico, Fernando (2014): “Introducción”, en Ernesto Caballero, Auto. Sentido del deber. Naces consumes mueres. Edición de Fernando Doménech Rico, Madrid, Cátedra, pp 9-126.

Lázaro Carreter, Fernando (1988): “Squash, de Ernesto Caballero”, Blanco y Negro (17 de julio).

López Martínez, Fernando (2014): La tradición deconstruida: clasicismo y modernidad en el teatro de Ernesto Caballero, UNED [Tesis doctoral].

Mayorga, Juan (2016): Elipses. Ensayos 1990-2016, Segovia, La uÑa RoTa.

Oliva, César (2004): La última escena (Teatro español de 1975 a nuestros días), Madrid, Cátedra.

Ordóñez, Marcos (2016): “Juana la Cuerda lo cuenta todo”, El País. Babelia (21 de mayo). Pérez-Rasilla, Eduardo (2003): “El teatro desde 1975”, en Javier Huerta Calvo (Dir.): Historia del teatro español, Madrid, Gredos, vol. II, pp. 2855-2883. 
